Pacific Journal of Mathematics

A PROPERTY OF MANIFOLDS COMPACTLY EQUIVALENT TO

R. J. Tundra 


\title{
A PROPERTY OF MANIFOLDS COMPACTLY EQUIVALENT TO COMPACT MANIFOLDS
}

\author{
R. J. TONDRA
}

\begin{abstract}
In this paper it is shown that there is a countable collection $\mathscr{G}=\left\{G_{k}\right\}_{k=1}^{\infty}$ of connected $n$-manifolds such that any manifold $M$ which is compactly equivalent to a compact manifold is an open monotone union of some $G_{\alpha(M)} \in \mathscr{C}$.
\end{abstract}

In [4] it is shown that if $\mathscr{F}$ is the class consisting of all open 2 -manifolds of finite genus, then there is a countable collection $\mathscr{D}=$ $\left\{D_{k}\right\}_{k=1}^{\infty}$ of open 2-manifolds with the property that given $M \in \mathscr{F}$, there exists some $D_{j} \in \mathscr{D}$ such that $M$ is an open monotone union of $D_{j}$. By appropriately extending the concept of genus to higher dimensions, one can obtain similar results for a larger class of manifolds.

1. Preliminaries. Unless otherwise specified, all manifolds will be assumed to be connected and bd $M$ and int $M$ will denote the boundary and interior respectively of a manifold $M$. Let $M$ and $N$ be $n$-manifolds. $M$ and $N$ are compactly equivalent, denoted by $M \sim{ }_{c} N$, if given any proper compact set $K \subset M$ there is an embedding: $i$ of the pair $(K, K \cap$ bd $M)$ into $(N$, bd $N)$ such that $i(K \cap$ bd $M)=$ $i(K) \cap \operatorname{bd} N$ and given any proper compact set $L \subset N$ there is an embedding $j$ of $(L, L \cap$ bd $N)$ into $(M$, bd $M)$ such that $j(L \cap$ bd $N)=$ $j(L) \cap$ bd $M$. Clearly compact equivalence is an equivalence relation on the class of all $n$-manifolds. Note that a 2 -manifold $M$ without boundary has finite genus if and only if $M \sim_{c} Q$ where $Q$ is some closed 2-manifold.

Let $\mathscr{L}$ be the class consisting of all non-compact $n$-manifolds $M, n \geqq 2$ and $n \neq 4$, such that $M \in \mathscr{L}$ if and only if $M \sim{ }_{c} N, N$ a compact manifold. The principal result of this paper is the following:

THEOREM 1.1. There is a countable collection $\mathscr{G}=\left\{G_{k}\right\}_{k=1}^{\infty}$ of manifolds such that given $M \in \mathscr{L}$ there is some positive integer $\alpha(M)$ such that $M$ is an open monotone union of $G_{\alpha(M)}$.

As usual an $n$-manifold $M$ is called an open monotone union of an $n$-manifold $H$ if $M=\bigcup_{i=1}^{\infty} H_{i}$ where for all $i, H_{i}$ is open in $M$, $H_{i} \subset H_{i+1}$ and $H_{i} \equiv H$ ( $\equiv$ denotes topological equivalence).

2. Proof of the theorem. If $M$ is an $n$-manifold, let $I(M)$ rel bd $M=\{f \mid f$ is a homeomorphism of $M$ onto itself such that $f$ is isotopic to the identity relative to bd $M$ \}. 
The following lemma gives the existence of a complicated domain which is the basic tool used in the construction of the collection $\mathscr{G}$ mentioned in Theorem 1.1.

Lemma 2.1. Let $E$ be an $n$-cell, $n \geqq 2$. There exists a proper domain (open connected set) $G$ of $E$, bd $E \subset G$, such that if $U$ is open in $E$ and $K$ is a proper continuum, bd $E \subset K \subset U$, then there exists a $g \in I(E)$ rel bd $E$ such that $K \subset g(G) \subset U$.

\section{Proof. This follows immediately from Lemma 3.8 of [5].}

Lemma 2.2. Let $Q$ be a compact $n$-manifold, $n \geqq 2$. There is a proper domain $D$ of $Q$ such that if $U$ is open in $Q$ and contains a residual set $R$ of $Q$, and $K$ is proper continuum in $Q, R \subset K \subset U$, then there exists $h \in I(Q)$ rel bd Q such that $K \subset h(D) \subset U$.

Proof. Let $E$ be a bicollared $n$-cell, $E \subset \operatorname{int} G$, and let $G$ be a proper domain $G$ of $E$ which satisfies the conditions of Lemma 2.1. We will show that $D=(Q-E) \cup G$ is the required domain. Without loss of generality, we may assume that $U$ is connected. Since $U$ contains a residual set $R$ (see [3] for appropriate definition) there is a bicollared $n$-cell $E^{\prime}$ and $\alpha \in I(Q)$ rel bd such that $R \subset Q-\operatorname{int} E^{\prime} \subset U$ and $\alpha\left(E^{\prime}\right)=E$. Note that $E$ and $\alpha$ can be obtained as follows: one easily constructs $\gamma_{1}, \gamma_{2}$, and $\gamma_{3} \in I(Q)$ rel bd $Q$ such that $\gamma_{1}$ only moves points inside $E \cup($ collar of bd $E$ ) and shrinks $E$ to a very small set, $\gamma_{2}$ moves $\gamma_{1}(E)$ into the open $n$-cell $Q-R$, and $\gamma_{3}$ moves only points inside $Q-R$ and expands $\gamma_{2}\left(\gamma_{1}(E)\right)$ so that $Q-U \subset \gamma_{3}\left(\gamma_{2}\left(\gamma_{1}(\right.\right.$ int $\left.E)\right) \subset$ $Q-R$. Thus we can set $\alpha^{-1}=\gamma_{3} \gamma_{2} \gamma_{1}$ and $E^{\prime}=\alpha^{-1}(E)$. Let $R \subset K \subset U$, $K$ a proper continuum. Without loss of generality, we may assume that $K \cap E^{\prime}$ is a proper continuum in $E^{\prime}$ and bd $E^{\prime} \subset K \cap E^{\prime}$. Then $K^{\prime \prime}=\alpha\left(K \cap E^{\prime}\right)=\alpha(K) \cap E$ is a proper continuum in $E, U^{\prime \prime}=\alpha(U) \cap$ $E=\alpha\left(U \cap E^{\prime}\right)$ is open in $E$ and bd $E \subset K^{\prime \prime} \subset U^{\prime \prime}$. Therefore it follows from Lemma 2.1 that there is a homeomorphism $h \in I(E)$ rel bd $E$ such that $K^{\prime \prime} \subset h(G) \subset U^{\prime \prime}$. Now extend $h$ to all of $Q$ by defining $h(x)=x$, $x \in Q-E$. Then $\alpha(K) \subset h(D) \subset \alpha(U)$ and so $g=\alpha^{-1} h$ is the required homeomorphism.

Since there are only a countable number of topologically distinct compact manifolds [1], Theorem 1.1 follows immediately from the following theorem.

Theorem 2.3. Let $Q$ be a compact $n$-manifold, $n>1$ and $n \neq 4$. There is a domain $D$ of $Q$ such that if $M$ is a non-compact n-manifold and $M \sim{ }_{c} Q$, then $M$ is an open monotone union of $D$. 
Proof. Let $D$ be a domain of $Q$ which satisfies Lemma 2.2. and let $L=Q$ - int $E, E$ a bicollared $n$-cell contained in int $Q$. Let $M$ be a non-compact $n$-manifold such that $M \sim{ }_{c} Q . \quad$ It is easily seen that bd $M=\operatorname{bd} Q$ and that there is an embedding $f$ of $(L$, bd $Q)$ into $(M$, bd $M$ ) such that $f\left(\right.$ bd $E$ ) (note that bd $E=L-\operatorname{int}_{Q} L$ where $\operatorname{int}_{Q} L$ denotes the point set interior of $L$ relative to $Q)$ is a bicollared $(n-1)$ sphere in int $M$. Since $M$ is an $n$-manifold, there exists a sequence $\left\{C_{i}\right\}_{i=1}^{\infty}$ of continua in $M$ such that $M=\bigcup_{i}^{\infty}, C_{i}$ and for all $i \geqq 1, f(L) \subset$ int $_{M} C_{i} \subset C_{i} \subset \operatorname{int}_{M} C_{i+1}$. Since $M$ is not compact and $M \sim_{c} Q$, for each $i \geqq 1$ there is an embedding $h_{i+1}$ of $\left(C_{i+1}\right.$, bd $\left.M\right)$ into $(Q$, bd $Q)$ such that bd $Q \subset h_{i+1}(f(L)) \subset h_{i+1}\left(C_{i}\right) \subset h_{i+1}\left(\right.$ int $\left._{M} C_{i+1}\right)$, where $K_{i}=h_{i+1}\left(C_{i}\right)$ is a proper continuum in $Q$ and $U_{i}=h_{i+1}\left(\right.$ int $\left._{M} C_{i+1}\right)$ is open in $Q$. Since $n \neq 4$, it follows from [2] that $\mathrm{Q}-h_{i+1}\left(f\left(\operatorname{int}_{Q} L\right)\right)$ is a bicollared $n$-cell and therefore there is a residual set $R$ of $Q$ such that $R \subset K_{i} \subset U_{i}$. It follows from Lemma 2.2 that there exists $\alpha_{i} \in I(Q)$ rel bd $Q$ such that $K_{i} \subset \alpha_{i}(D) \subset U_{i}$. Define $\beta_{i}: D \rightarrow M$ by $\beta_{i}(x)=h_{i+1}^{-1}\left(\alpha_{i}(x)\right)$. Then $\beta_{i}$ is an embedding of $(D$, bd $Q)$ into $(M$, bd $M)$ and $C_{i} \subset \beta_{i}(D) \subset \operatorname{int}_{M} C_{i \mid 1}$. Therefore $M=\bigcup_{i}^{\infty}, \beta_{i}(D)$, where $\beta_{i}(D)$ is open and $\beta_{i}(D) \subset \beta_{i+1}(D)$ for all $i \geqq 1$. Therefore $M$ is an open monotone union of $D$.

The author would like to thank the referee for his helpful suggestions.

\section{REFERENCES}

1. J. Cheeger and J. M. Kister, Counting topological manifolds, Topology, 9 (1970), 149-151.

2. C. O. Christenson and R. P. Osborne, Pointlike subsets of a manifold, Pacific J. Math., 24 (1968), 431-435.

3. P. H. Doyle and J. G. Hocking, A decomposition theorem for n-dimensional manifolds, Proc. Amer. Math. Soc., 13 (1962), 469-471.

4. R. J. Tondra, Characterization of connected 2-manifolds without boundary which have finite domain rank, Proc. Amer. Math. Soc., 22 (1969), 479-482.

5. —, Engulfing continua in an n-cell, Trans. Amer. Math. Soc., 158 (1971). 465-479.

Received April 5, 1971 and in revised form June 18, 1971.

Iowa State UNIVERSity 



\section{PACIFIC JOURNAL OF MATHEMATICS}

\section{EDITORS}

\author{
H. SAMELSON \\ Stanford University \\ Stanford, California 94305 \\ C. R. HOBBY \\ University of Washington \\ Seattle, Washington 98105
}

\section{J. DuGundJI}

Department of Mathematics University of Southern California Los Angeles, California 90007

RICHARD ARENS

University of California

Los Angeles, California 90024

\section{ASSOCIATE EDITORS}
E. F. BECKENBACH
B. H. NeumanN
F. WOLF
K. YOSHIDA

\section{SUPPORTING INSTITUTIONS}

\author{
UNIVERSITY OF BRITISH COLUMBIA \\ CALIFORNIA INSTITUTE OF TECHNOLOGY \\ UNIVERSITY OF CALIFORNIA \\ MONTANA STATE UNIVERSITY \\ UNIVERSITY OF NEVADA \\ NEW MEXICO STATE UNIVERSITY \\ OREGON STATE UNIVERSITY \\ UNIVERSITY OF OREGON \\ OSAKA UNIVERSITY
}

\author{
UNIVERSITY OF SOUTHERN CALIFORNIA \\ STANFORD UNIVERSITY \\ UNIVERSITY OF TOKYO \\ UNIVERSITY OF UTAH \\ WASHINGTON STATE UNIVERSITY \\ UNIVERSITY OF WASHINGTON \\ AMERICAN MATHEMATICAL SOCIETY \\ NAVAL WEAPONS CENTER
}

The Supporting Institutions listed above contribute to the cost of publication of this Journal, but they are not owners or publishers and have no responsibility for its content or policies.

Mathematical papers intended for publication in the Pacific Journal of Mathematics should be in typed form or offset-reproduced, (not dittoed), double spaced with large margins. Underline Greek letters in red, German in green, and script in blue. The first paragraph or two must be capable of being used separately as a synopsis of the entire paper. The editorial "we" must not be used in the synopsis, and items of the bibliography should not be cited there unless absolutely necessary, in which case they must be identified by author and Journal, rather than by item number. Manuscripts, in duplicate if possible, may be sent to any one of the four editors. Please classify according to the scheme of Math. Rev. Index to Vol. 39. All other communications to the editors should be addressed to the managing editor, Richard Arens, University of California, Los Angeles, California, 90024.

50 reprints are provided free for each article; additional copies may be obtained at cost in multiples of 50 .

The Pacific Journal of Mathematics is published monthly. Effective with Volume 16 the price per volume (3 numbers) is $\$ 8.00$; single issues, $\$ 3.00$. Special price for current issues to individual faculty members of supporting institutions and to individual members of the American Mathematical Society: $\$ 4.00$ per volume; single issues $\$ 1.50$. Back numbers are available.

Subscriptions, orders for back numbers, and changes of address should be sent to Pacific Journal of Mathematics, 103 Highland Boulevard, Berkeley, California, 94708.

PUBLISHED BY PACIFIC JOURNAL OF MATHEMATICS, A NON-PROFIT CORPORATION

Printed at Kokusai Bunken Insatsusha (International Academic Printing Co., Ltd.), 270, 3-chome Totsuka-cho, Shinjuku-ku, Tokyo 160, Japan. 


\section{Pacific Journal of Mathematics}

\section{Vol. 42, No. $2 \quad$ February, 1972}

Stephen Richard Bernfeld, The extendability of solutions of perturbed scalar differential equations ................................. 277

James Edwin Brink, Inequalities involving $f_{-} p$ and $f^{(n)}{ }_{q}$ for $f$ with $n$

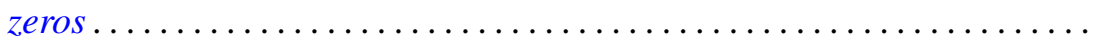

Orrin Frink and Robert S. Smith, On the distributivity of the lattice of filters of a groupoid

Donald Goldsmith, On the density of certain cohesive basic sequences .... 323

Charles Lemuel Hagopian, Planar images of decomposable continua . . . . . 329

W. N. Hudson, A decomposition theorem for biadditive processes ........ 333

W. N. Hudson, Continuity of sample functions of biadditive processes......

Masako Izumi and Shin-ichi Izumi, Integrability of trigonometric series.

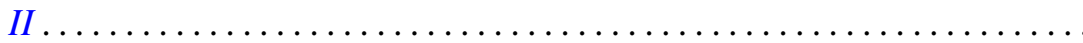

H. M. Ko, Fixed point theorems for point-to-set mappings and the set of

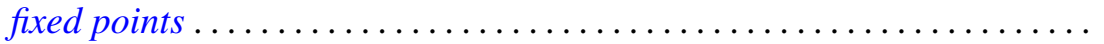

Gregers Louis Krabbe, An algebra of generalized functions on an open interval: two-sided operational calculus ...

Thomas Latimer Kriete, III, Complete non-selfadjointness of almost selfadjoint operators.................................

Shiva Narain Lal and Siya Ram, On the absolute Hausdorff summability of a Fourier series .

Ronald Leslie Lipsman, Representation theory of almost connected groups...

James R. McLaughlin, Integrated orthonormal series.... . .

H. Minc, On permanents of circulants.

Akihiro Okuyama, On a generalization of $\Sigma$-spaces.....

Norberto Salinas, Invariant subspaces and operators of class $(S)$

James D. Stafney, The spectrum of certain lower triangular matrices as operators on the $l_{p}$ spaces .......................

Arne Stray, Interpolation by analytic functions

$\mathrm{Li} \mathrm{Pi} \mathrm{Su}$, Rings of analytic functions on any subset of the complex plane.

R. J. Tondra, A property of manifolds compactly equivalent to compact manifolds.... 